\title{
Brain and Language: an overview of neuroimaging studies of bilingual language processing
}

Augusto Buchweitz

Programa de Pós-Graduação em Inglês (PPGI)

Universidade Federal de Santa Catarina

Seis artigos que combinam o estudo de bilíngües e técnicas de neuroimagem são discutidos. O objetivo, em suma, é buscar uma contribuição de estudos de neuroimagem para o entendimento do que se passa no cérebro de bilíngües ao utilizarem duas línguas, e como essas línguas se comportam em relação às áreas de ativação do cérebro. Estudos mostram que ao atingir um nível elevado de proficiência na segunda língua, ambas as línguas utilizadas ativam áreas semelhantes no cérebro, o que indica, por sua vez, que a segunda língua passa a fazer parte do conhecimento procedimental, ou automatizado.

Six articles combining the study of bilinguals and neuroimaging techniques are discussed. The objective is to seek for contributions from neuroimaging studies for the understanding of what goes on in the bilingual brain that processes two languages, and of what goes on, comparatively, in terms of brain activation of each language. Studies show that highly proficient bilinguals activate the same areas in the brain for both the first and second languages. This indicates that the second language becomes part of the speaker's procedural knowledge.

\section{Introduction}

Proficiency and age of acquisition - two well-known factors that tell bilinguals apart - determine brain organization of the processing of different languages and the extent of reliance on procedural (implicit) versus declarative (explicit; metalinguistic) knowledge. Stemming from a contribution by Paradis (2003) to the book Mind, Brain, and Language: multidisciplinary perspectives, this paper collects findings from a number of neuroimaging studies (Positron-Emission Tomography-PET and functional Magnetic Resonance Imaging-fMRI) to address the issue of differential activation of cerebral mechanisms (cortical areas activated) 
in early versus late bilinguals. The early bilingual (EBL) is one who acquires a second language from early childhood. The late bilingual (LBL), in turn, is one who acquires or learns a second language after the age of seven years (PARADIS, 2003, p.352). The factor of language proficiency, rather than age of acquisition/learning alone, is also assessed to compare the activation of cerebral mechanisms between bilinguals (for example, PERANI, PAULESU, GALLES, DUPOUX, DEHAENE, BETTINARDI, CAPPA, FAZIO, and MEHLER, 1998).

Six articles are discussed, in chronological order (Table 01). First, Kim, Relkin, Lee, and Hirsch (1997) on the cortical representation of different languages in the brain; second, Perani, Paulesu, Galles, Dupoux, Dehaene, Bettinardi, Cappa, Fazio, and Mehler (1998) on proficiency and age of acquisition; third, Illes, Francis, Desmond, Gabrieli, Glover, Poldrack, Lee, and Wagner (1999) on semantic processing; fourth, Hernandez, Martinez, and Kohnert (2000) on language switching; fifth, Hasegawa, Carpenter, and Just (2002) on bilingual processing and cognitive workload; and, finally, sixth, Marian, Spivey, and Hirsch (2003) on phonetic and lexical processing in bilinguals. A short glossary can be found at the end of the article.

\section{Kim, Relkin, Lee, and Hirsch (1997)}

The authors show that there is a similarity in frontal-lobe cortical representation of the first and second languages in EBLs, and a distinguished representation in LBLs. Similarly to Paradis (2003), Kim, Relkin, Lee, and Hirsch's (1997) rationale for investigating the cortical representation of languages in bilinguals stems from findings of patients with insults to the classical left perysilvian language areas (Broca's and Wernicke's area) showing better recovery of the second language, instead of the native language. According to Paradis (2003), LBL's better recovery of the second language after insult to the language areas (related to procedural knowledge) is evidence of an increased reliance on declarative (metalinguistic) knowledge in the second languagewhich is spared considering that declarative knowledge is related to hippocampal and medial temporal lobe structures, and the amygdala (PARADIS, 2003, p.357). 
Table 01: Articles discussed

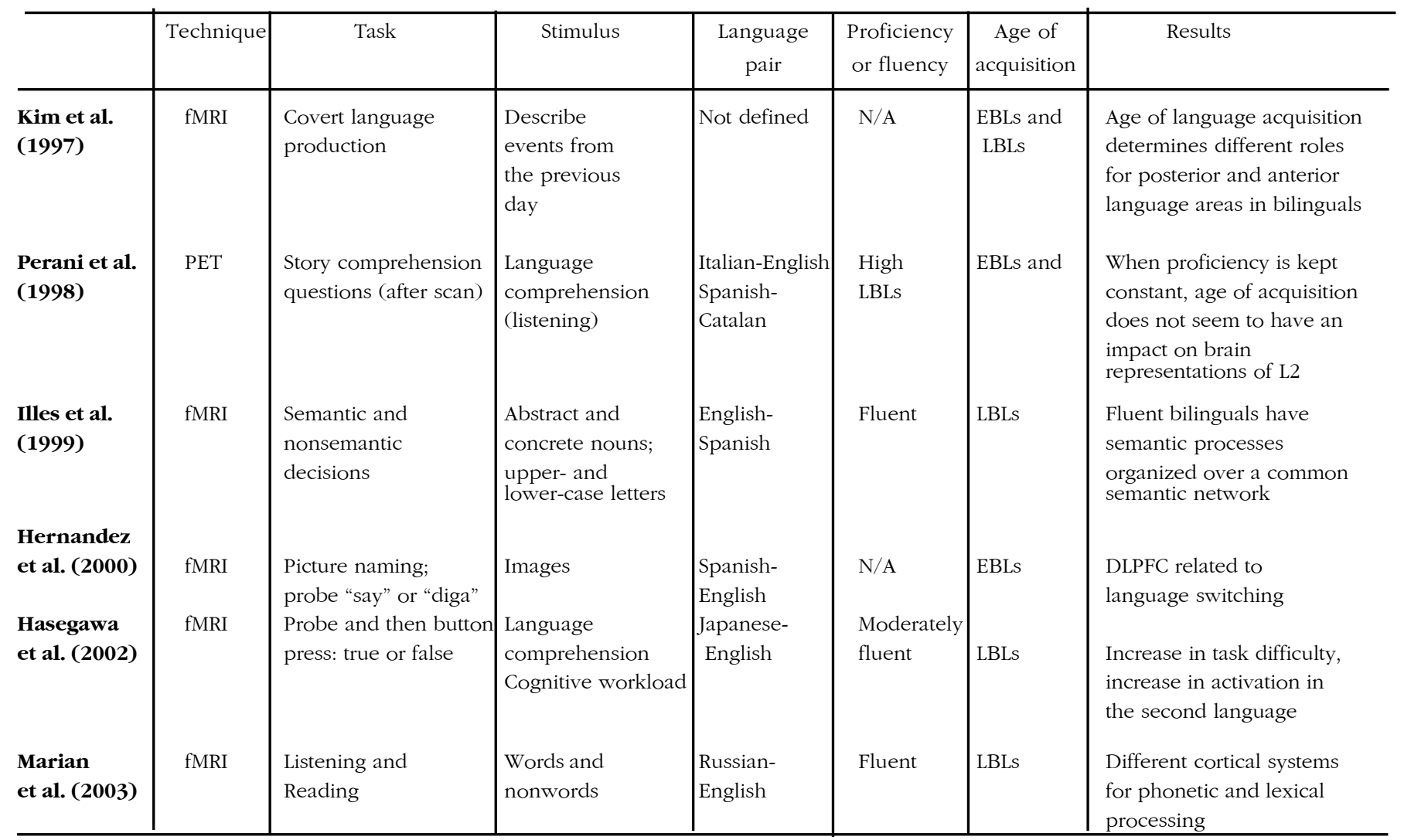


In the study, imaging of LBLs, while performing a covert production task, showed spatially distinct activation in anterior language areas (Broca's) for the first and second languages (KIM, RELKIN, LEE, and HIRSCH, 1997, p.171); the posterior language areas (Wernicke's), however, showed almost no separation of activation for both LBLs and EBLs (KIM, RELKIN, LEE, and HIRSCH, 1997, p.172). In sum, age of language acquisition appears to determine different roles for posterior and anterior language areas in bilinguals. But subsequent studies will show that proficiency, rather than merely age of acquisition, is also important.

\section{Perani, Paulesu, Galles, Dupoux, Dehaene, Bettinardi, Cappa, Fazio, and Mehler (1998)}

The nine authors carried out a PET investigation of both age of acquisition and proficiency in bilinguals. Strikingly, different ages of acquisition did not result in differential cortical response; rather, proficiency in the second language is the factor at play. Comparison of the patterns of activation while listening to the first language and backward speech (baseline), and to the second language and backward speech showed no significant differences between high-proficiency LBLs and EBLs. The areas activated (left temporal pole; middle and posterior temporal gyri; bilateral hippocampal structures) were similar in both populations. Direct first and second language comparison of EBLs, however, showed activation in hippocampal structures for the second language (possibly due to reliance on declarative knowledge) (PERANI, PAULESU, GALLES, DUPOUX, DEHAENE, BETTINARDI, CAPPA, FAZIO, and MEHLER, 1998, p.1845).

There is one important difference to be noted in relation to Kim, Relkin, Lee, and Hirsch (1997). In that study, participants performed a production task; in this, however, they performed a listening task. The difference in activation in anterior language areas (Broca's, classically related to production), which Kim, Relkin, Lee, and Hirsch (1997) failed to find in the posterior areas (Wernicke's, related to comprehension) could be related to the tasks performed (PERANI, PAULESU, GALLES, DUPOUX, DEHAENE, BETTINARDI, CAPPA, FAZIO, and MEHLER, 1998, p.1846). But this does not mean that age of acquisition is not a 
factor in second language acquisition; rather, the authors conclude that "when proficiency is kept constant, age of acquisition per se does not seem to have an impact on (macroscopic) brain representations of L2" (PERANI, PAULESU, GALLES, DUPOUX, DEHAENE, BETTINARDI, CAPPA, FAZIO, and MEHLER, 1998, p.1849). The two studies, however, did not require much in the sense of decision-making during the tasks performed. In this sense, the next study investigated semantic and nonsemantic decisions in bilinguals.

\section{Illes, Francis, Desmond, Gabrieli, Glover, Poldrack, Lee, and Wagner (1999)}

Drawing on previous neuroimaging studies (including the two previous studies), and on behavioral data, the authors take advantage of the spatial resolution afforded by fMRI to investigate whether first and second languages share a common semantic network in fluent LBLs (second language fluency acquired, on average, ten years after first language acquisition) (ILLES, FRANCIS, DESMOND, GABRIELI, GLOVER, POLDRACK, LEE, and WAGNER, 1999, p.351). In this sense, participants performed semantic (concrete-abstract nouns) and nonsemantic (upper- or lowercase letters) decisions in English and Spanish. The experiment was performed in three runs: with English semantic and nonsemantic decisions; with Spanish semantic and nonsemantic decisions; and with a block design alternating between English and Spanish semantic decisions, allowing for direct comparison (ILLES, FRANCIS, DESMOND, GABRIELI, GLOVER, POLDRACK, LEE, and WAGNER, 1999, p.353).

Behavioral results showed participants performing at ceiling in semantic judgments in both languages. Neuroimaging results, in turn, showed greater activation for semantic versus nonsemantic decisions in the left inferior frontal gyrus (Broca's area) in both the first and second language. As predicted, direct comparison of the two languages showed no consistent patterns of differential activation across languages (ILLES, FRANCIS, DESMOND, GABRIELI, GLOVER, POLDRACK, LEE, and WAGNER, 1999, p.354). Thus, as far as fMRI resolution allows, the authors conclude that fluent bilinguals have semantic processing organized over a common cortical network (ILLES, FRANCIS, 
DESMOND, GABRIELI, GLOVER, POLDRACK, LEE, and WAGNER, 1999, p.356).

The study thus extends and corroborates previous findings of common cortical networks for both the first and second languages. The results from semantic decision tasks differ from those from comprehension and covert production tasks in that they indicate - even if a second language is learned at an older age - that the brain systems recruited for processing meaning are the same in the first and second languages: age of acquisition does not appear to be a determinant factor in differential activation between languages in highly fluent bilinguals. Considering, thus, that there is a common semantic network shared between languages, how does the bilingual speaker prevent confusion between languages?

\section{Hernandez, Martinez, and Kohnert (2000)}

If bilinguals activate similar cortical areas for both languages, "[...] how is it that bilinguals keep information from one language from consistently interfering with processing of information in the other language?" (HERNANDEZ, MARTINEZ, and KOHNERT, 2000, p. 423). A metaphorical answer to this question: the language switch. To address the question of language switching, the authors applied the fMRI technique with a group of EBLs naming pictures in Spanish and English. The experiment was conducted in three different runs, with and without fMRI data collection. Two block designs were carried out for each language (being the cues "say" and "diga") and one mixed condition, alternating between languages. The regions-of-interest (ROIs) were the dorsolateral prefrontal cortex (DLPFC), the supramarginal gyrus, the inferior frontal gyrus (Broca's), and the superior temporal gyrus (Wernicke's) (HERNANDEZ, MARTINEZ, and KOHNERT, 2000, p. 424).

Results from data collection without fMRI (behavioral) showed a main effect of language: response times were faster for English (HERNANDEZ, MARTINEZ, and KOHNERT, 2000, p.426). Results from the neuroimaging experiment showed significant activation only in the left DLPFC; with homologous bilateral activation (both right and left hemispheres) in four of the six subjects. There were no significant 
differences in activation between languages (HERNANDEZ, MARTINEZ, and KOHNERT, 2000, p. 427).

In searching for the language switch, thus, the authors found that the DLPFC, among the ROIs studied, is significantly activated in language-switching tasks. Instead of trying to find the language switch, it seems that executive functions are the determinant factors in successful language switching. For example, other neuroimaging studies relate the DLPFC and executive functioning in maintenance and manipulation tasks (HERNANDEZ, MARTINEZ, and KOHNERT, 2000, p. 428; D'ESPOSITO, POSTLE, BALLARD, and LEASE, 1999; CARPENTER, JUST, and REICHLE, 2000). It is not without reason, thus, that the authors found the DLPFC to be related to switching between two languages. They conclude stating that the search for the language switch in the brain will most likely turn out empty-handed.

Switching between languages involves brain areas across several domains, and the significant DLPFC activation is related to attentional control required to switch between codes (HERNANDEZ, MARTINEZ, and KOHNERT, 2000, p.429). Additionally, in relation to the previous studies, results did not show differential activation of brain areas between languages, but they do suggest that if there are differences, they may lie beyond the spatial resolution afforded by fMRI (HERNANDEZ, MARTINEZ, and KOHNERT, 2000, p.429).

Semantic decisions and language switching were the additions of the two previous studies to the investigation of the cortical organization of languages in bilinguals. In the next study, Hasegawa, Carpenter, and Just (2002) address the issue of cognitive workload.

\section{Hasegawa, Carpenter, and Just (2002)}

Fluent EBLs and LBLs activate an overlapping cortical system for both the first and second languages. In this study, the authors posit an additional question, that is, whether manipulating the cognitive workload required of bilinguals will result in different activation between two languages. The workload hypothesis finds support in brain imaging studies showing that activation is affected by cognitive workload. In this sense, the authors hypothesize that, in moderately fluent bilinguals, second language comprehension is potentially more difficult than first 
language comprehension and will thus elicit more brain activation (HASEGAWA, CARPENTER, and JUST, 2002, p. 648). Workload was thus considered to vary in terms of first and second language and, additionally, using affirmative (easier) and negative (harder) sentences in both languages (HASEGAWA, CARPENTER, and JUST, 2002, p. 649).

The ROIs were Wernicke's and Broca's areas (HASEGAWA, CARPENTER, and JUST, 2002, p. 651). Language comparison yielded a degree of activation overlap varying from 51 to 74 percent of voxels, in terms of identical areas activated, and from 69 to 100 percent in terms of adjacent and identical areas. Hence, there was a high degree of intersecting cortical tissue between the two languages (HASEGAWA, CARPENTER, and JUST, 2002, p. 652).

Computational workload, however, affected activation only in the second language (though behavioral data showed that participants had a tougher time with negative sentences in both languages): The increase in voxels activated in the left temporal region was statistically significant only in English (the second language of the participants). According to the authors, this result may be ascribed to greater difficulty in processing negative sentences in the second language. Results also showed a functional connection between the statistically-significant activation in the left temporal region and other areas that showed similar patterns of increased activation (left precentral sulcus). Differences in activation in the right hemisphere were not statistically significant (HASEGAWA, CARPENTER, and JUST, 2002, p. 655).

The authors conclude that increased activation in the second language, and the additional areas recruited are attributable to the greater difficulty in processing sentences in the second language, as participants presumably try to achieve the same level of comprehension in both languages. From the behavioral and neuroimaging studies and results discussed, it appears that cognitive workload influences the recruitment of additional cortical tissue in second language processing (HASEGAWA, CARPENTER, and JUST, 2002, p. 657).

The combination of behavioral and neuroimaging data is very important in the sense of corroborating, outside brain imaging, the hypothesis governing findings of differences or similarities in brain activation. As seen above, Hasegawa, Carpenter, and Just (2002) relied on time measures of processing of negative sentences to postulate that 
they are more difficult than affirmative sentences. The next study, in this sense, takes this combination of sources a step further, combining eyetracking technique and neuroimaging.

\section{Marian, Spivey, and Hirsch (2003)}

Marian, Spivey and Hirsch combine behavioral (eyetracking) and neuroimaging (fMRI) data while postulating that the shared cortical structures found in bilinguals are characteristic of earlier stages of processing (phonetic); but that later stages (lexical) may actually recruit different cortical systems (MARIAN, SPIVEY, and HIRSCH, 2003, p. 70). In other words, the cognitive architecture for phonetic processing operates simultaneously between two languages, whereas that for lexical processing may elicit differential activation (MARIAN, SPIVEY, and HIRSCH, 2003, p. 71).

In the eyetracking experiment, Russian-English bilinguals received auditory instruction to pick up objects which were either presented with a phonetic competitor (homophones) in either language, or not (an example of phonetic competitor: "marka," which means "stamp" in Russian, and "marker" in English (MARIAN, SPIVEY, and HIRSCH, 2003, p. 73)). Results showed that participants looked at competitor objects more often than at non-competitor items and, thus, that there is parallel processing in both languages at the early stage of comprehension (MARIAN, SPIVEY, and HIRSCH, 2003, p. 75).

Stemming from the eyetracking results, fMRI data collection was applied to investigate bilingual processing at the cortical level. Visual and auditory presentation of words was applied to compare phonological and lexical processing. The ROIs were the classical language areas: Inferior Frontal Gyrus and Superior Temporal Gyrus. Participants were fluent, LBLs.

Results showed increased activation in the left inferior frontal gyrus for the second language in the phonologic, and bilateral increased activation in the same area for the lexical processing task. Also, different centers-of-mass of activation were observed within languages (MARIAN, SPIVEY, and HIRSCH, 2003, p.79), that is, different middle points in the total areas activated. There were no differences in activation in the superior temporal gyrus, which was active - as 
expected considering its relation with comprehension - only in the phonological task.

In sum, the neuroimaging results showed similarities and differences in bilingual processing. In the words of the authors, the similarities related to areas and patterns of activation, corroborating the previously-discussed studies; the differences, however, related to greater activation in the second language (possibly corroborating Hasegawa, Carpenter, and Just (2002) above in their discussion on cognitive workload), and different centers-of-mass in activation in Broca's area (MARIAN, SPIVEY, and HIRSCH, 2003, p. 81). In conclusion, as later stages of processing activated slightly different areas of the left inferior frontal gyrus, the authors postulate that this may indicate that later stages of processing recruit different cortical areas, whereas the earlier ones, which operate in parallel, operate over similar areas of the brain.

\section{Conclusion}

The studies discussed ranged from investigating factors of age of acquisition to workload, and phonetic and lexical processing. In general, when factors of age of acquisition and (high) proficiency are controlled, it appears that bilinguals activate similar cortical areas across the brain. This is evidence that in proficient bilinguals the second language has become a skill, procedural knowledge. It is important, however, not to discard clinical evidence (PARADIS, 2003) showing better recovery of the second language in stroke patients. This finding may be well related to the first study discussed (KIM, RELKIN, LEE, and HIRSCH, 1997), in which the authors identified different centers-of-mass for the activation in early and late bilinguals and, thus, that there is greater reliance on declarative knowledge in the second language (though the authors did not control for proficiency).

As expected, proficiency in the second language was also determinant in relation to areas of brain activation. According to the studies, as higher proficiency is achieved, bilinguals apparently activate the same areas in both the first and second languages - thus indicating that knowledge has become automatized (PERANI, PAULESU, GALLES, DUPOUX, DEHAENE, BETTINARDI, CAPPA, FAZIO, and MEHLER, 
1998; ILLES, FRANCIS, DESMOND, GABRIELI, GLOVER, POLDRACK, LEE, and WAGNER, 1999). Hence, as the acquisition or learning of a second language is still in earlier stages of proficiency, it appears that there is a greater reliance on declarative knowledge on the part of bilinguals. However, as proficiency improves (and here it is important to bear in mind that there are different ways to understand improvement in one's second language proficiency and ability), brain imaging studies indicate that both the first and the second languages are processed in similar cortical areas. In other words, second language processing in the brain becomes similar to that of the first language.

Workload was found to increase brain activation in harder sentences in the second language (HASEGAWA, CARPENTER, and JUST, 2002). Though the harder sentences in this particular study did not evoke more activation from the participants in their first language, others have manipulated sentence complexity and found greater activation in the mother tongue alone (JUST, CARPENTER, KELLER, EDDY, and THULBORN, 1996). Finally, with the discussion that there may be levels of processing in common between languages (MARIAN, SPIVEY, and HIRSCH, 2003), and that as deeper levels of processing are required, so are different areas of the brain recruited, it is clear that the investigation of bilinguals applying neuroimaging techniques still has a lot of questions to answer, such as those elicited by workload and difficulty (levels) of processing, by whether differential activation is evoked in these cases, and by the ability to switch between, and comprehend, two languages.

Returning to Paradis (2003), the factors of age of acquisition and proficiency are relevant in the discussion of neuroimaging data. As the author indicated, it is important not to forget about behavioral data, for the assumptions made are only as strong as the theoretical framework adopted (PARADIS, 2003). This paper sought for studies with bilinguals and it appears that not only is there room for more investigation in the area, but also that the study of bilinguals with neuroimaging may be a fruitful testbed for language studies, in the sense that it will afford new insights into what bilinguals, or language learners, do with the language. 


\section{Glossary}

Broca's area

Wernicke's area

Cortex

$D L P F C$

Executive functions:

Maintenance task

Manipulation task

Voxels
The inferior frontal gyrus, area of the human cortex involved in language processing, speech production, and comprehension (named after Paul Broca).

The superior temporal gyrus, area of the human cortex involved in understanding and comprehension of spoken language (named after Carl Wernicke).

The outer layer of the brain (gray matter), or the surface of the brain.

Dorsolateral prefrontal cortex.

There are five functions, (1) focusing attention ("attention and inhibition"); (2) switching attention between tasks ("task management"); (3) planning a sequence of subtasks to accomplish some goal ("planning"); (4) updating and checking the contents of working memory ("monitoring"); and (5) coding representations in working memory for time and place ("coding") (SMITH and JONIDES, 1999, p. 1659).

A task that requires maintaining information over a period of time, for example, a string of letters (AVQW).

A task that, in addition to maintaining information, requires that it be manipulated over a period of time, for example, after being shown a string of letters one has to remember the letters and put them in alphabetical order.

A three-dimensional pixel. It represents 3D data just as a pixel represents a point or cluster of points in $2 \mathrm{D}$ data (on a computer screen, for example).

\section{References}

D'ESPOSITO, M.D.; POSTLE, B.R.; BALLARD, D.; LEASE, J. Maintenance versus manipulation of information held in working memory: An eventrelated fMRI study. Brain and Cognition, v. 41, p. 66-86, 1999.

HERNANDEZ, A.E.; MARTINEZ, A.; KOHNERT, K. In search of the language switch: An fMRI study of picture naming in Spanish-English bilinguals. Brain and Language, v. 73, p. 421-431, 2000.

HASEGAWA, M.; CARPENTER, P. A.; JUST, M. A. An fMRI study of bilingual sentence comprehension and workload. Neuroimage, v. 15, p. 647-660, 2002. 
ILLES, J.; FRANCIS, W. S.; DESMOND, J. E.; GABRIELI, J. D. E.; GLOVER, G. H.; POLDRACK, R.; LEE, C. J.; WAGNER, A. D. Convergent cortical representation of semantic processing in bilinguals. Brain and Language, v. 70, p. 347-363, 1999.

JUST, M. A.; CARPENTER, P. A.; KELLER, T. A.; EDDY, W. F.; THULBORN, K. R. Brain activation modulated by sentence comprehension. Science, v. 274, p. 114-116, 1996.

KIM, K. H. S.; RELKIN, N. R.; LEE, K.; HIRSCH, J. Distinct cortical areas associated with native and second languages. Nature, v. 388, p. 171-174, 1997.

MARIAN, V.; SPIVEY, M.; HIRSCH, J. Shared and separate systems in bilingual language processing: Converging evidence from eyetracking and brain imaging. Brain and Language, v. 86, p. 70-82, 2003.

PARADIS, M. Differential use of cerebral mechanisms in bilinguals. In: BANICH, M.T.; MACK, M. (Eds.) Mind, Brain, and Language: Multidisciplinary perspectives. London: Lawrence Erlbaum, 2003.

PERANI, D.; PAUlESU, E.; GALLES, N. S.; DUPOUX, E.; DEHAENE, S.; BETTINARDI, V.; CAPPA, S. F.; FAZIO, F.; MEHLER, J. The bilingual brain: proficiency and age of acquisition of the second language. Brain, v. 121, p. 1841-1852, 1998.

SMITH, E. E.; JONIDES, J. Storage and executive processes in the frontal lobes. Science. 283, 1657-, 1999. 